\title{
Written Academic Discourse in English: From local Traditions to Global Outreach
}

\begin{abstract}
The text discusses the position of local academic traditions in the modern context of global academic discourse dominated by the Anglo-American rhetorical style that represents the standard for modern international academic communication. After reviewing some of the central notions attached to the discipline of genre analysis of written academic discourse, the paper argues for an extension of the traditional research agenda by calling for a broad sociolinguistics of genre. It is suggested that sociological, ethnographic, cross-cultural, translatological, pedagogical and critical approaches may enrich the current understanding of written academic genres. They can do so by revealing some of the ideologies and implicit norms on which particular disciplines rely in the discursive production and reproduction of knowledge, as well as the textual practices present in the transformation, recontextualization, translation, editing, etc., that may affect the eventual form of the academic texts produced, in particular, by non-native scholars coming from other cultural and academic backgrounds than the dominant global English-language model.
\end{abstract}

Key words

Academic discourse; written academic genres; English for Academic Purposes; sociolinguistics of genre; cross-cultural academic communication

\section{Local traditions and global discourse}

Genre analysis has been the dominant paradigm for the study of academic discourse over the past two decades. In this conception, genres are conceived of functionally as configurations of expected forms and meanings that a given community associates with particular situations and acknowledges as distinct from 
each other. This view of genres as institutional social practices that are groupbased and goal-oriented derives from some of the seminal studies in the field, in the tradition established by Swales (1990, 2004), Bhatia (1993), and others, that has been readily taken up by ESP theoreticians and practitioners (cf. DudleyEvans and St. John 1998, Hyland 2009). The broad social purposes that connect professionals communicating in diverse genres through a variety of different text types are, as is argued by Hyland (2012), "a key element of the context of a text and the rationale of a genre; they help to shape the ways it is structured and the choices of content and style it makes available."

Although the global communication within professional communication may be carried out through the medium of English, it is, however, rooted in the local traditions of academic discourse that frequently operate under different social and discursive norms than the globally dominant Anglo-American system (cf. Duszak 1997). International scholars are, thus, operating in a situation that may be marked by a sort of "substrate" influence of their native-language background. They may even find themselves drawing on different academic and discursive traditions, depending on the audience they are addressing: the international audience of scholars to whom they write in English or (arguably) the more local audience addressed in their academic texts produced in languages other than English.

There are several perspectives one can adopt with respect to such written academic production. A descriptive, anthropological view may be concerned with the establishment of the essentialist characteristics of the respective cultural traditions that may be postulated to exist either on national or trans-national levels (cf. the elaboration of contrasts along such lines as the Anglo-American vs. Germanic $v s$. Slavic cultures, etc., that can lead to the identification of 'typical' rhetorical forms of such traditions, cf. Čmejrková and Daneš 1997). In this way, deviations from the discursive patterns expected in the target language academic culture may be symptomatic of the underlying forms and structures that are characteristic of the academic tradition in the other culture.

On the other hand, there is also the pedagogic approach that - deriving from the descriptive observation of differences between the source and the target cultures of academic discourse - occasionally shows a preoccupation with prescriptive pronouncements, because it may, with varying degrees of explicitness, aim to assist in teaching diverse competencies in the "target" discourse. In this view, the researcher maps the deviations from the normative usage postulated in the genres of the target culture. Perhaps not surprisingly, the pedagogic orientation is present in many linguistically-oriented studies of written academic discourse undertaken from a cross-cultural perspective, because such a focus may help to justify the practical motivation of much of the research: findings about different cultural traditions - translated into the notions of interference, transfer, etc. - are used to increase the competence of students (cf. Hyland 2008: 60).

That is certainly a noble goal, though potentially open to criticism on account of implicitly condoning the cultural dominance of English that derives from its unrivalled position of a global lingua franca (Swales 1997 even warns of the pos- 
sible loss of professionally-marked registers in some cultures). It is, after all, easy to dismiss what might be a different academic cultural tradition seeping through a text written in English merely as "a lack of competence" or "ignorance of genre norms", rather than to insist on cultural relativism or genre flexibility reflecting different audiences, etc. Particularly in the humanities, the situation is, of course, complicated by the fact that there may not be a single pattern or formulaic structure that could be used as a mould to be filled with content in the case of articles or other written genres. While the expectations of the degree of writers' adherence to conventional discursive patterns may differ in various academic disciplines, there is the further complication that experts may also differ from novices in the way they write.

The current situation that is marked by the dominance of the Anglo-American norm in the globalized academia is compounded by the traditionally privileged role of standard British and American English and the model position of the native speaker. Though the traditional view has been changing over the past few decades, native speakership is still very much taken as the benchmark against which the linguistic proficiency of non-native speakers is assessed, which also includes the area of academic discourse. That is despite the fact that a recent paradigmatic shift in linguistic thinking has led to an increased empowerment of non-native speakers using English as a lingua franca. For instance, Seidlhofer (2011) argues that native speakers are no longer the sole arbiters on the proper use of English. English as a lingua franca (ELF), as used by non-native speakers, is seen not as a priori incorrect or deviant but, rather, a creative use of the language in its own right. Similarly Mauranen (2012), who operates with the concept of English as an Academic Lingua Franca (EALF) in her study of spoken academic discourse, argues that the ownership of the language has expanded to non-native communities that use ELF in their encounters with each other.

That, however, does not mean that such concepts as correctness have become outdated. It is true that it is relatively less important in interactions among non-native ELF speakers who are generally more permissive (or less aware) of linguistic imperfections as long as they communicate smoothly and efficiently. Nevertheless, despite such limits to one's linguistic skills, the model of native-speaker level proficiency (often equated with Standard English correctness) is implicitly present even in those interactions. As Mauranen (2012: 5) notes, ELF speakers may not share a cultural background, though they may possess "shared ... cultural identities and expectations relative to target language speakers, [and] English-speaking countries". The 'inner circle' countries are then viewed by learners "against their own cultural background for comparison, contrast, and models of target appropriateness".

In written academic discourse, linguistic, rhetorical and genre norms are not only expected but are also actively enforced. Although editors tend to be supportive of non-native contributions, basing their editorial decisions on content rather than what is evidently incorrect language use, research articles are often referred to linguistic services for proofreading and language editing. The British linguist 
and editor Greg Myers even reports an incident when he received his manuscript from an editor with the suggestion that the article should be checked by a native speaker, possibly after perceiving some of the "oddities in [the author's] style as the result of second language interference" (2012: 149). He also notes that, while referees are relatively not very specific when complaining about the level of English in a given manuscript, usually commenting on obvious mistakes and matters of style (errors, heavy constructions, ambiguities, prescriptivist usage dictums) and on the results of interference from other languages (missing articles, inconsistent tense, unidiomatic prepositions, etc.), they may also, as Myers stresses, "be encountering a different cultural rhetoric for academic articles, and feeling the need for the deductive structure, understated references, and hedging characteristic of academic publication in what might be called the Anglo-American tradition" (2012: 150).

The research on written academic discourse is, thus, positioned at the intersection of several major approaches, including genre theory, rhetorical structure, cross-cultural communication, English as a lingua franca (ELF), language pedagogy, the sociology and politics of science, etc. Let us now turn our attention to the specific linguistic topics addressed by the individual authors in this volume, pointing out how their findings and conclusions contribute to the overall theme of written academic communication across different cultural traditions. This overview of the papers is followed by a reflection on the possible directions of some future research, which argues for the extension of focus from formal, structural, rhetorical and pragmatic phenomena resident in written academic texts towards a dynamically conceived sociolingustics of genre that takes into account the social, professional, textual and intertextual contexts of production and reception of written academic discourse as well as its institutional and social embedding.

\section{Written academic discourse: Anglo-American traditions in the European context}

The present collection comprises eight original research studies that provide some novel insights into written academic discourse produced in English in several European countries (Spain, the Czech Republic, Italy and Serbia) and South Africa. All the authors analyse academic materials written in English by scholars who are non-native speakers of English, often contrasting their material against control sets of data produced by established or aspiring native scholars. While the individual authors understandably differ in their research questions as well as the data sets that they exploit in pursuing their aims, they all approach the material from the broad perspective of genre analysis that has been embraced by mainstream linguists over the past two decades as a suitable approach to the study of academic discourse. Thus, the authors share a general functional understanding of academic genres as established ways in which scholars textually interact with each other in their professional communities. 
In the first article in the collection, Savka Blagojević and Biljana Mišić Ilić perform a contrastive pragmatic analysis of interrogatives in English and Serbian academic discourse. For the purposes of comparison, the research draws on three sets of data: English academic articles written by native speakers of English, English academic articles written by native speakers of Serbian, and Serbian academic articles written by native speakers of Serbian. The quantitative analysis of the data reveals that Serbian writers use more interrogatives than English scholars, doing so both in their native language and when writing texts in English. This finding is interpreted as an instance of rhetorical transfer from the writers' native academic culture. The authors complement their findings with a pragma-linguistic analysis of the functions of interrogatives, partly confirming Hyland's earlier finding (2004) that the form helps to increase the readers' dialogic involvement with the text, and partly noting that the functions arise out of the combination of positional, syntactic, semantic and pragmatic factors. In their data, for instance, rhetorical interrogatives often occur at the beginning of paragraphs, and some may contain instances of inclusive we to draw attention to a specific point.

Olga Dontcheva-Navratilova tackles the issue of lexical bundles in novice academic writing, by focusing on Master's theses written by Czech students of English. Based on a list of lexical bundles pre-selected from previous studies on the topic, the author establishes the frequency of the bundles according to their basic types (referential, discourse organizers, attitudinal). It is shown that lexical bundles in academic writing produced by novice non-native writers manifest several interesting features: (a) there is noticeable structural variation (particularly in prepositional-phrase and noun-phrase elements), (b) occasional grammatical errors render some of the bundles inaccurate, and (c) the relatively much less frequent use of bundles is accompanied by a different distribution of the functional categories. Those findings stand as evidence of the writers' insufficient level of rhetorical skills and interference from L1 writing conventions.

The issue of cross-cultural aspects of academic discourse is the primary focus of the paper by Maurizio Gotti, who addresses the issue in the context of the ongoing globalization of socio-cultural and communicative practices. Noting that academic discourse is far from uniform, Gotti locates its realizations at the intersection of numerous factors such as local culture, disciplinary field, generic conventions, community membership, language competence, professional expertise and even gender. Writing in the English-dominated global context, scholars have been found not only to adapt to Anglo-centric models but also to show resistance in the textual strategies through which they construct their identity. It is stressed that academic genres manifest a degree of flexibility that allows authors to negotiate their position in specific socio-professional contexts rather than to adhere to the strict formal requirements of particular genres. Reporting the results of the CERLIS research group, Gotti illustrates his point by tracing identity traits that can be linked to cross-cultural aspects of academic discourse in four genres: journal editorials, book reviews, research articles, and legal articles. It appears that authors may exhibit transversal identities, marking their affiliation to various 
cultures (professional, ideological, ethnic-geographic); the intercultural clashes may, thus, result in hybridizing forms on the level of concrete textual realizations.

The genre of the book review is also addressed in detail in the article by Rosa Lorés-Sanz, who analyzes evaluation in reviews published in British and Spanish history journals. The author operates with the functional unit of an "evaluative act", tracing its lexicogrammatical realizations in both positive and negative contexts. The analysis shows that evaluation is used rather differently in the two communities: Spanish historians appear to treat reviews as a site for bonding with their peers rather than for knowledge construction. This is because they not only refer comparatively more to the book's author than to the book's contents as the subject of their reviews, but they also practically exclude all negative evaluation. What is particularly valuable is that Lorés-Sanz has also carried out a small ethnographic study among book reviewers and editors, with the aim of obtaining an inside view of the values ascribed to the genre of the review and the different understanding of its role in British and Spanish academic contexts. Similar to Gotti, Lorés-Sanz then concludes that the expected matching between the national culture, national science and the relevant audience, which forms the anticipated configuration in a given academic community, may be disrupted when academics either write in a different language (e.g., English) than is common for that community, or they address their text to a different audience (e.g., international rather than national/local researchers). The fact that the mismatch may result in having one's text refused for publication underlies the different nature of academic discourse in the two communities.

The pragmatic concept of evaluation is also pursued in the article by Enrique Lafuente Millán, who reports the results of a study of attitudinal evaluation in research articles written in English and Spanish across three disciplines. This type of self-evaluation is crucial in the academic community, in that scholars need to use certain linguistic rhetorical strategies in order to persuade other colleagues, as well as editors, of the value of their work: the high quality of one's work is not enough, and the scholarly content needs to be suitably marketed through evaluative and persuasive language. Using the methodology of quantitative contrastive analysis, it is shown that article writers use different evaluative strategies depending on the context of publication. Different fields evidently have different norms and expectations concerning self-evaluation; this finding is explained in reference to the stronger competition found in some disciplines (such as in business management, as opposed to applied linguistics). Since the data single out Spanish research articles from those written in English, the author suggests that, after taking into account their different (local) audience, they might be viewed as a separate subgenre with a distinct generic integrity.

The transfer of non-native scholars' writing practices from their first language into English is also discussed by Pilar Mur-Dueñas in her text on business management research articles written by Spanish scholars for the international audience. The focus is on the writers' use of topicalizers, i.e., linguistic signals that organize the discourse and contribute to the cohesion of texts, as deployed in 
three sets of texts that are analysed here: articles composed by Anglo-American scholars publishing in their native English, by Spanish scholars publishing in English, and by Spanish scholars publishing locally. The quantitative data reveal that, while native speakers tend to use topicalizers mostly in Introduction and Discussion sections, Spanish authors not only concentrate them predominantly in the Results section but also show a much higher overall frequency of their use. The study confirms that L2 scholars transfer some features of textual organization from their native academic culture, although there appear to be limits to such a rhetorical transfer. That is because editing, proofreading or simply the scholars' awareness of the target norms in the globalizing discourse community serves to ensure a degree of homogeneity in the genre.

A similar textual feature is studied by Renata Povolná, who deals with discourse markers in students' diploma theses written in English. The quantitative analysis of causal and contrastive discourse markers reveals that novice writers tend to make a number of common mistakes, such as being unable to distinguish between hypotactic and paratactic markers, overusing certain markers, beginning too many discourse segments with a marker, having a limited repertoire of markers, and selecting markers from the wrong registers. It is suggested that the fact that learners tend to express causal and contrastive relationships in an overt way when organizing their discourses can be explained with reference to the learners' insecurity about the proper use of the relevant discourse markers. Having been exposed to various aspects of academic composition in university courses, novice non-native writers may be characterized as having unstable writing habits and as exhibiting personal preferences that frequently do not correspond to the correct use of discourse markers in written academic discourse.

In the last paper in the collection, Josef Schmied addresses the issue of the presentation of knowledge in students' writing. Working with a corpus of South African MA theses from various disciplines, he explores several linguistic forms (personal pronouns, modal auxiliaries, cohesive linkers) that are crucial for establishing a discourse connection between novice writers and the academic community that they are striving to convince of their knowledge through the presentation of relevant facts. The quantitative analysis of the linguistic forms is linked to a number of variables that include not only the various disciplines but also the writers' linguistic/ethnic background (reflected, for instance, in the tendency of Black South African speakers to use plural pronouns more frequently) and gender (apparently affecting pronominal choice as well). As a result, the study is also interesting from a sociolinguistic point of view, since it maps linguistic variation at the interface between use-related and user-related varieties of English.

\section{Expanding the research agenda}

Many of the papers in this collection arrive at similar conclusions, namely documenting that academic genres are not static configurations of set lexico-gram- 
matical features but dynamic constructs through which writers participate in the scholarly discourse of their community of practice, project their professional identities, and seek to convince and persuade others of their epistemic claims in the given discipline. It is evident that members of different communities share different normative expectations about the preferred modes of communication, although such norms are rarely formulated openly. Instead, they rely on their prior experience with genres that require scholars to tune sensitively into the rhetorical patterns common in their disciplines as well as their national/local academic traditions. Researchers are aware of this patterned variability, since they are frequently able to manipulate some of the features (typically those they perceive as salient for a given genre), depending on the nature of the community that they are addressing. In this sense, they engage in a form of audience or speaker design (Bell 1984, Coupland 2001), since they display stylistic variability as a response to the anticipated context in which their academic texts will be processed.

Adopting this view, it is easy to see how some non-native scholars, whether experts or novices, may find it hard to negotiate the rhetorical and discursive norms - despite the norms' inherent flexibility and dynamism - in genres with which they have had little prior experience. That concerns not only foreign students struggling with their theses but also experienced academics who, while used to working in their native languages and cultures, face novel problems when composing in a different target language, namely English as the global lingua franca of academic communication. It is then no wonder that non-native writers may possess a more limited linguistic and rhetorical repertoire than native speakers, since they may consciously stick to several forms (e.g., certain discourse markers) that they may have been exposed to through explicit schooling, and then use those forms either excessively or incorrectly. That situation is, once again, not quite unlike the sociolinguistic phenomenon of hypercorrection. At the same time, however, there is the unconscious transfer of certain forms and patterns from their native (i.e., non-English) cultural traditions that a sufficiently detailed linguistic analysis may bring to light.

There is much space for further research in this area, particularly in the "grey zones" surrounding genre boundaries and the extent of genre variability. While it is clear that non-native writers will, in their textual production, divert from the expected, yet flexible patterns in the diverse academic genres of English, it remains to be seen which of those departures will prove to be within the limits of acceptability and which not, resulting instead in the perception of a given text as marked and non-conforming to the discourse norms of the international academic community. However, variation need not always come as the result of an imperfect approximation of the implicit and often indistinct norms of an external academic culture. It can also be the outcome of personal idiosyncrasy or authorial freedom of expression, though produced within the bounds considered tolerable by the community. It would, therefore, be useful to see how such idiosyncratic texts are handled - not only when they are drafted by non-native writers but also when they are authored by experienced native speakers of English. It is not clear 
how members of the professional community or the community's gate-keepers interpret instances of such non-conformity: Do they view them negatively (as an imperfect mastery of the target norms that should be improved and corrected), positively (as the praiseworthy act of innovative language use and possibly textual foregrounding), or neutrally (as the acknowledgement of the potential transfer of external academic norms or simply the acceptance of the diversity of personal academic styles)?

Questions like these underlie the need for a systematic research agenda that may call, for instance, for ethnographically-oriented studies of editorial practices in international journals. Such a focus may help to identify the discursive norms and ideologies on the basis of which a relevant segment of a certain discipline operates. At the same time, there is, arguably, a need and a potential to expand genre studies of academic discourse by exploring not just textual features but also the broader discourses that surround the production of knowledge in academia. Various approaches from critical discourse analysis can certainly throw more light on practices such as textual transformations, textual borrowing on the discursive level, as well as the industrialization of the processes of knowledge production and dissemination on the more general level of social practice. What is more, such practices may be distributed differently in different geographical areas, which can be characterized by quite diverse patterns of academic discourse (cf. Tarasheva 2011). Publishing in English is no longer a simple act of sharing and disseminating knowledge: it is a part of the academic politics, being closely tied to one's professional career and employment options. For non-native speakers of English based in their local academic cultures, foreign publications may serve as an important asset in promotions and output evaluations (cf. Lillis and Curry 2010; Fanghanel 2012).

Likewise, suitable tools are needed for the study of variation on the level of individual authors. Thus, research into academic discourse should trace the development of the textual and discursive competences of individual authors across their careers, as well as document the possible occurrence of structural and rhetorical templates that some authors may re-use in several academic texts. After all, few scholars produce articles that are entirely independent: writers tend to develop their ideas, sometimes recycling parts of their previous texts while recontextualizing them and enriching them with novel insights and fresh data. The publishing trajectory of an individual scholar, then, often resembles a situation in which the individual articles are pushing the status quo of his or her knowledge and understanding of a given issue forwards through small incremental steps, often across rather prolonged periods of time.

As was suggested above, more attention also needs to be paid to how written academic discourse comes into existence, i.e., to explore the ways academic articles and other outcomes of scholars' written discourse are produced. Although the actual data may be much more difficult to obtain - requiring genre analysts to either approach other writers to let them follow their text-production processes (e.g., by making various drafts available to them) or to carry out self-directed 
research on their own writing practices - the aspects of academic discourse that happen "behind the scenes", in the privacy of an individual's research, certainly hold some promising findings. While the process of academic writing is inevitably messy, with texts produced in a non-linear manner, the final polished product with which genre analysts typically work will have gone through several stages of reading, rewriting and editing by the writer and possibly others (colleagues, editors, etc.). The situation becomes even more complicated in the case of articles authored by non-native speakers seeking language services such as proofreading from native speakers (cf. Myers 2012: 150). Articles co-authored by several scholars (often from various countries) may be a special case in point: the authors will strive to achieve a smooth textual flow in such co-authored texts, even though the writing is sometimes not seamless, and although slightly different styles may emerge in textual segments authored by different writers.

Additionally, it is customary for scholars in many countries to write their articles in their mother tongue and have them translated into English, especially in those cases when they intend the texts for international audiences. Thus, while such writers may compose an academic text that fully corresponds to the local/ national norms and fits the expected lexico-grammatical and rhetorical patterns in the writer's native academic culture, the same situation might not correspond with the translated text. That is the observation made by many of those who have been asked to translate texts by non-native writers into English. The translator faces the dilemma of what approach to take with respect to the translation, particularly in regard to what extent he or she may (or should) modify the original in terms of its textual and rhetorical structure in an attempt to make it correspond more closely to the conventions of the target academic culture, thereby increasing the article's chances of publication. In some cases, it suffices to make some more or less surface-level adjustments; in other cases, more significant textual reorganization is needed, and the translator may need to communicate with the author to suggest changes and improvements. Where a different academic tradition combines with a generally low-quality presentation of content (muddled formulations, an uncorrected draft, lack of clear structure, etc.), the translator may even need to work closely with the author to oversee a process that essentially amounts to rewriting the text. However, there is a lot of interaction with the text that remains offstage, and it is at that precise point where different academic styles, as well as different levels of experience, clash.

Lastly, apart from sociolinguistic, ethnographic, critical, cross-cultural and translatological approaches, the area of genre analysis of written academic discourse in cross-cultural contexts has an important practical dimension that surfaces in its strong pedagogic orientation. Many studies in the field provide recommendations for teaching, pointing out the infelicities and mistakes committed by second-language learners and novice writers against the background of the mainstream model represented by instances of academic genres produced by native speakers. The tutoring of L2 students in the style of the Anglo-American academic discourse should, however, be taken neither as an act of cultural im- 
perialism nor as an academic exercise simply helping those students to produce suitable output needed for obtaining their degrees. Only a tiny minority of students, after all, will pursue academic careers in later life and will actually write academic papers themselves after graduation. Rather, instruction and guidance in the styles and genres of written academic discourse in English will help students to acquire skills that are proving increasingly indispensable in the modern marketplace. It can develop their sensitivity to different styles, cultivate their ability to switch between diverse styles, and enhance their skills in formulating spoken and written messages in ways that are maximally effective and take into account the context of the target culture/situation/audience. In this sense, the pursuit of linguistic research in terms of academic genres across different cultural and national traditions is highly topical.

\section{References}

Bell, Allan (1984) 'Language style as audience design'. Language in Society 13, 145-204.

Bhatia, Vijay K. (1993) Analysing Genre: Language Use in Professional Settings. London: Longman.

Coupland, Nikolas (2001) 'Language, situation, and the relational self: Theorizing dialect-style in sociolinguistics'. In: Eckert, Penelope and John R. Rickford (eds.) Style and Sociolinguistic Variation. Cambridge: Cambridge University Press, 185-210.

Čmejrková, Světla and František Daneš (1997) 'Academic writing and cultural identity: the case of Czech academic writing'. In: Duszak, Anna (ed.) Culture and Styles of Academic Discourse. Berlin and New York: Mouton de Gruyter, 41-61.

Dudley-Evans, Tony and Maggie Jo St. John (1998) Developments in English for Specific Purposes: A Multi-disciplinary Approach. Cambridge: Cambridge University Press.

Duszak, Anna (1997) ‘Cross-cultural academic communication: A discourse-community view’. In: Duszak, Anna (ed.) Culture and Styles of Academic Discourse. Berlin and New York: Mouton de Gruyter, 12-39.

Fanghanel, Joëlle (2012) Being an Academic. London and New York: Routledge.

Hyland, Ken (2004) 'Patterns of engagement: dialogue features and L2 undergraduate writing'. In: Ravelli, Louise and Robert Ellis (eds.) Analyzing Academic Writing: Contextualized Frameworks. London: Continuum, 5-23.

Hyland, Ken (2008) 'Academic clusters: text patterning in published and postgraduate writing'. International Journal of Applied Linguistics 18 (1), 41-61.

Hyland, Ken (2009) Academic Discourse. London: Continuum.

Hyland, Ken (2012) 'Genre and Discourse Analysis in Language for Specific Purposes'. In: Chapelle, Carol A. (ed.) The Encyclopedia of Applied Linguistics. Blackwell Publishing. DOI: 10.1002/9781405198431.wbeal0452

Lillis, Theresa and Mary Jane Curry (2010) Academic Writing in a Global Context. The Politics and Practices of Publishing in English. London and New York: Routledge.

Mauranen, Anna (2012) Exploring ELF: Academic English Shaped by Non-native Speakers. Cambridge: Cambridge University Press.

Myers, Greg (2012) 'English. Whose English?’ Discourse, Context \& Media 1, 149-150.

Seidlhofer, Barbara (2011) Understanding English as a Lingua Franca. Oxford: Oxford University Press.

Swales, John (1990) Genre Analysis: English in Academic and Research Settings. Cambridge: Cambridge University Press. 
Swales, John (1997) 'English as a Tyrannosaurus Rex'. World Englishes 16 (3), 373-382.

Swales, John (2004) Research Genres. New York: Cambridge University Press.

Tarasheva, Elena (2011) 'The place of Eastern European researchers in international discourse:

Critical discourse analysis applied to corpora from specialized journals'. Discourse and Society 22 (2), 190-208.

JAN CHOvANEC is Assistant Professor of English Linguistics at Masaryk University in Brno. Specializing in discourse analysis, stylistics and pragmatics, with a focus on media communication and legal discourse, he has dealt with such issues as multimodality, humour and the representation of social actors in the press. He has written extensively on discursive strategies in the British media and on the novel genre of online sports commentary. He co-edited the book Language and Humour in the Media (together with Isabel Ermida, Cambridge Scholars Publishing, 2012) and co-authored Soudni překlad a tlumočeni [Court Translation and Interpreting] (together with Miroslav Bázlik and Teodor Hrehovčík, Wolters Kluwer, 2011).

Address: Mgr. Jan Chovanec, Ph.D., Department of English and American Studies, Faculty of Arts, Masaryk University, Arna Nováka 1, 60200 Brno, Czech Republic. [chovanec@phil.muni.cz] 